\title{
Globalization, the Internet and Guilty Pleasures in Morocco
}

\author{
Mansour Pourmehdi \\ Department of Sociology, Manchester Metropolitan University, United Kingdom
}

Copyright (C) 2015 by authors, all rights reserved. Authors agree that this article remains permanently open access under the terms of the Creative Commons Attribution License 4.0 International License

\begin{abstract}
This paper explores the ways in which the internet as the engine of globalization contributes to the spread of a global culture by transforming traditional cultural values. Morocco has been at the crossroad of globalising forces for sometimes, yet the cultural values that treat men and women differently remain strong. Using questionnaires and interviews, this research finds that the internet facilitates the breakdown of traditional boundaries that militate against sharing space and mixing with the opposite sex. The internet acts as a medium, which empowers individuals to behave in ways that breach Moroccan social norms, allowing young people to evade traditional barriers to romance by sidestepping cultural taboos without breaking them.
\end{abstract}

Keywords Globalization, the Internet, Networks, Cultural Homogenization, Romance, Life Styles

\section{Introduction}

Globalization refers to the movement of people, capital, information, life styles and ideologies [1]. The internet has been viewed by some as an engine of globalization [2,3] whilst scorned by others as heralding cultural imperialism [4]. For others, the internet is celebrated as a tool that overcomes the dualism of the local and the global [5]. It has been argued that Western culture has been spreading to other cultures, and this cultural invasion has particularly affected global youth because they are technologically capable and computer savvy. It is claimed that the internet helps to alienate people from their local culture and heritage. The internet and the media are also effective political tools that can manipulate people's views and opinions [6]. The internet is not objective and free of values [7,8]. Thus, for some observers the internet is a tool at the service of imperialism, which enhances cultural, economic and political empowerment of the West. Indeed, technology in general is vital to globalization and there could be no globalization without it.

One view is that the rapid growth of the internet around the world will accelerate the spread of global culture whilst others believe that the internet is very much compatible with traditional cultural values. A global culture is not a bigger version of culture of a nation state but refers to;

Trans-societal cultural processes which take a variety of forms, some of which have preceded the inter-state relations into which nation-states can be regarded as being embedded, and processes which sustain the exchange and flow of goods, people, information, knowledge and images which give rise to communication processes which gain some autonomy on a global level. Hence, there may be emerging sets of 'third cultures'. [9] p.1.

It has been argued that the global culture, one approximating the cultures of Europe and North America, based on freedom of speech and consumerism, pursuit of pleasure will spread around the world as the internet penetration grows [1].

"Globalization is diffusing a single world culture centered on consumerism, mass media, Americana and the English language" [10] p.26. Although, the notion of a global culture is hard to define, it refers to the ways in which people around the world share certain values and life styles, sharing similar media and consumer products due to dilution of local and national cultures by globalizing forces, notably, digital communication, satellite television and the Internet, which know no national borders and governmental control, "Many national controls over information have become ineffective. People everywhere are exposed to the values of other cultures as never before" [11] p.17.

The spectre of a world culture dominated by western values and consumerism has alarmed a number of academics including Hannerz [12], Canclini [13], Howes [14], Tomlinson [15], Ritzer [16]. One cannot ignore the availability and accessibility of western consumer and media products, which in turn provide access to western values and consumer life styles that on the surface appears as if the 
global culture is explicitly Westernization and Americanization.

It has been noted that in late modernity, people can select from a variety of life styles, and traditions and customs do not shape people's lives as they once did. The community in which they were born less influences people's identities. Communities of the past provided their members with solid guidelines, concerning how they should conduct their lives. Their communities influenced their values and ethics $[17,18]$. Globalization has brought the individual to the center. It is now up to the individual to construct her/his own identity. Caught in the midst of global flows, the burden of tradition and conventional values are declining, compelling us to redefine our identities, intimate relationships, and other aspects of our lives including our sexuality [19].

The extent to which globalisation is affecting family and intimate relationships through information technologies and the internet has been investigated by Padilla et al [20], Valentine [21], Ilouz [22]. This is reflected in Altman [23] who states that globalization leads to the relocation of difference. Consequently, people belonging to specific groups might find that they share more common interests with people in other parts of the world than those whom with they share the same geographical location. Similarly, Jackson [24] points to cultural differences and the significance of the local and contends that the economic supremacy of the West and its accompanying political influence does not fundamentally result in cultural domination of the world. On the other hand, while globalization is changing the world, our societies and our daily experiences; established institutions have often failed to keep up with these transformations. This paradox of change alongside tradition is nowhere more apparent in the case of sexual mores and particularly people in Muslim societies.

The idea that globalization is creating homogenous sexual identities has been challenged by Altman [23], Blackwood [25] and Jackson [24] amongst others. Commentators all agree that Western culture affects other cultures because of powerful media influences, yet they nevertheless, argue that the local and global interact with one another and often this lead to conflict and tension at the local level. The global culture has been created as the result of transnational cultural flows and media images. This enables people, especially, the youth to engage in romantic and sexual relationships that are not permitted outside marriage in traditional Muslim culture [26], yet marriage remains important, especially for women who increasingly wish to express themselves sexually but are constantly reminded of the need to remain a virgin. This paper aims to explore how adult Moroccans construe internet-mediated romance?

How Moroccan adults deal with social, cultural barriers to romance? In addition, to evaluate the extent to which global cultural homogenization regarding premarital sex and romance is taking place in Morocco.

\section{Attitudes towards Premarital Sexuality in Morocco}

Morocco is located in what used to be called the Maghreb in North Africa and has a population of 32,987,206 [27]. Morocco has a close relationship with Europe, particularly France her former colonial power. In the 1980's, Morocco embarked on economic reforms and ever since has exploited her geographical closeness to Europe and low labour costs in order to attract foreign investment and pursue an open market economy.

Islamic societies, compared with Western countries are conservative on matters such as sexuality, gender equality, etc. and highly oppose sexual freedom. This is reflected in their intolerant attitudes towards abortion, divorce and homosexuality [28]. The Moroccan culture is heavily influenced by Islamic values and tradition, and places a high value on family honour. The family's reputation is largely dependent on the conduct of its female members where an intact hymen symbolizes a proper family upbringing. Despite recent push towards modernization and economic growth, Morocco remains a conservative society in which premarital sex is illegal. Those unfortunate enough to be caught will face public humiliation as well as imprisonment.

In Morocco, family honour depends on the chastity of women $[29,30,26]$. Unmarried women and men often are prohibited from forming friendship without supervision. Like other MENA (Middle East and North Africa) countries, men belong to public space; they provide for their families by going to work and earning an income whilst women's place is often in the private space where they look after the home and family. Keeping women like this, in theory will help to ensure they remain a virgin, hence protecting family honour. It has been argued that Moroccan women are living in a society, which is dominated by men who control their sexuality, and in doing so increase their power and status. This view has been challenged by Venema \& Bakker [31] page 51 who state that;

In reality, among the Berber people of the Middle Atlas, many divorced and widowed women see no economic alternative to becoming a prostitute. Cultural and global conditions have made the area a permissive zone for prostitution because of the local tradition of ritual dances that act as a marriage market, the absence of a focus on virginity, and because retired prostitutes can regain the respect of their community. Since the 1960s, Moroccan migrants returning temporarily home and male tourists from neighbouring countries have given the Middle Atlas the permissive zone for prostitution.

Globalization and social reform have brought the opposite sexes in closer contact and this is evident in mixed schools and workplaces. Families have been responsible for passing down traditions and expect the children to uphold those values, although gender interaction has been tolerated, 
opposite sexes must refrain from dating and cannot meet unsupervised. The interaction should remain formal $[30,29,26]$.

Since the late $19^{\text {th }}$ century, modernization projects have enabled women In MENA countries to progressively enter into the public spaces. They have been allowed to study at universities, shop in the markets, work in clerical and administrative jobs and attend the mosque [30,32]. This shift has been accompanied by a fear that women in these countries would become corrupt and form sexual relationship outside conventional marriage. Women have never escaped the burden of honour and reputation placed on their shoulders. Indeed, women have to justify their entry into public places by not getting involved in situations that would threaten their respectability; their presence in public should symbolize the private [33].

It can be argued that women's appearance in the public sphere was induced by the need for modernization, and follows the Western model of development in which women play an important role in economic and political development [32]. It was deemed necessary to educate women and push them into public spaces so that they become more effective in the private realm as arbiters of national heritage. For national development, it was necessarily for women to enter the public domain but to preserve the national tradition women's sexuality had to be protected.

According to Mernissi [34] the explanation for this tension rests on the religious roots of Muslim family life, which holds women responsible for controlling their sexual instinct. There is no such limitation on men as they can have as many partners as they wish providing they can financially afford them. The processes of modernization, and globalization inevitably involved institutional changes, which led to a restructuring of the space allocated to women and to the gender integration, and ultimately the demise of the patriarchal control. High rates of unemployment resulted in a decline of family as a self-sufficient production unit, which drew on the labour of its members regardless of gender. Another factor that has contributed to the demise of patriarchy was the emigration of a large number of males in search of employment both nationally and internationally. In their involvement with various economic and educational activities, the sexes began to interact and experience dimensions of life that was not allowed previously under the patriarchal system. One consequence of this was that 'one of the most effective means of controlling pre-marital sex was being destroyed, and the control of sexual activity was becoming practically impossible [34].

However, the legal and cultural condemnation of pre-marital sex does not stop individuals to have sex, it happens regardless of the existing social, cultural, and legal barriers, as Morocco has become a destination for sexual tourism.

The increase in premarital and extramarital sexuality is somehow evident by the epidemiological situation of Aids in Morocco where there are as many single men with the infection as married people. Moroccan society appears to condemn prostitution as a plague on family order whilst at the same time tolerate prostitution because it enables the youth to experience sex, and the already married men to satisfy their erotic fantasies [35].

Recently, some sections of society have been alarmed by the way the youth explore their sexuality, influenced by Western culture. In a survey of young Moroccans, sixty-seven percent had a positive attitude towards marriage but $36 \%$ did not think about it because of adverse financial conditions [36]. Another survey found that $40 \%$ of young Moroccans voiced their concern regarding Islam and premarital sexual relations, due to the fact that too many are unemployed, lack educational qualifications, and have not enough resources to marry [35].

Bakass \& Ferrand [37] found that the majority of the men and women in their sample felt that women virginity would guarantee her future prospect of marriage. This belief seems to be largely common in Morocco. Bakass \& Ferrand concluded that sexual debut before marriage is becoming common amongst the younger generations.

Globalization vastly intensifies the importance of social networking in human life. The internet essentially provides an open, non-hierarchical, decentralized, borderless platform for creation of both formal and informal networks, enabling them to spread beyond the confines of particular localities. Global networks allow space to work for agents and institutions by linking and invigorating their previously separate practices. Globalization diminishes the constraints of time and space on our activities. The internet strengthens weak ties, making the physical distance between members less important, what matters most is staying connected as Castells [38] observes all kinds of global activity will come to depend on the internet and information technology.

Social networks connect a large number of participants whose interactions with each other fluctuate. Networking is fundamentally about forming relationships with people. Networks provide an avenue for people to accomplish relationships within a safe and secure environment. Although in theory, closed networks provide trust, safety, and security, nevertheless, it is in open networks where individuals can experiment with various life styles, and acquire skills and information that inevitably lead to independence. The internet provides both men and women access to global culture. This entry often is equated with becoming Western and a breach of traditional values.

\section{Methodology}

The city of Beni Mellal is the capital of the Béni Mellal-Khénifra Region. According to 2010 census, the city had a population of 489,248 (Wikipidia). The city was selected for this research because it is a small city with a tradition of migration. There are many families from whom at least one member has migrated to Europe and other countries. Their remittances have been influential for the 
growth and welfare of the community. Further, the city is becoming a popular destination for tourists, especially Europeans. Therefore, it was decided that it would be an ideal place to explore the impact of globalization. This study is based on a mixed design approach. The researcher believes that since the phenomenon under investigation was a complex and sensitive one, a mixed method approach would provide more insights and understanding and considered appropriate. Using a small-scale survey provided a general picture of the extent and reasons for using the internet and the characteristics of users whilst using qualitative interviewing shed light on people's actual experiences. The questionnaire was translated into Arabic and subsequently was administered to visitors of internet Cafés. Morocco has the third highest internet usage in Africa $(15,656,192$ users) after Nigeria with $(45,039,711$ users), and Egypt (21,691,776 users) [39]. The internet penetration in Morocco is (49\%), the highest in Africa [39]. Morocco is one of the most liberal countries with regard to the internet in Africa. However, internet freedom was restricted by the introduction of the anti-terrorism law in 2003. Internet cafes play a crucial role in Morocco; they provide access to computers and the internet for Moroccans, as a large number of citizens have no computer sets or internet connections. Thus, although connection to the internet is increasing, internet cafés remain the major means through which people access the internet. Many use internet cafés like ordinary coffee houses and as a place for meeting and socializing.

The qualitative study was based on in-depth interviews. We used the interviews to encourage participants to talk in details about their experience, trying to seek answers to exploratory sensitive questions from participants who were not familiar with social research.

In total ten interviews were conducted, six males and four females. The youngest informant was 24 years of age and the oldest was 42. Three female informants had Baccalaureate, one was a university student, and two were educated to degree level. All male informants had a university degree. Apart from a male and a female who were divorced, the rest have not been married before. In addition, an internet café owner was also interviewed in order to provide a general overview of how people use the internet. The analytical frame of this study is the grounded theory approach. A theoretical sampling [40,41] was used. Theoretical sampling;

Is the process of data collection and generating theory whereby the analyst jointly collects, codes, and analyses his data and decides what data to collect next and where to find them, in order to develop his theory as it emerges [42] p.45.

Theoretical sampling involves purposive sampling of participants, looking for people and groups where the phenomena could be studied, taking into account the diversity within the given population. The informants were selected based on their experience, individuals who already had experience of online romance; relationship and global networking were identified. Therefore, the researcher was able to select different type of informants who possessed relevant experience. The sampling strategy was not guided by a preference for generalizing participants experience of online romance, but by a quest for understanding.

Fictional names are used to protect respondents' identities.

\section{Findings and Discussion}

In total 176 questionnaires were completed, $45 \%$ by men and $55 \%$ by women. Eighty seven percent of respondents were between the ages of 15 to 26 whilst $13 \%$ were over 27 year of age. Thirty five percent of respondents spent more than six hours per day on the internet. The majority of respondents used the internet for sending and receiving emails (75\%), whilst $88 \%$ said that they use the internet for research and finding information. Only $38 \%$ went on the net to find jobs. Using the internet to play games online was not as popular $(39 \%)$ while watching movies $(57 \%)$ and listening to music (91\%) was more attractive to the respondents. Nearly half read the daily news online.

A sizable majority (84\%) used the internet for chatting and $58 \%$ of males had a partner of the opposite sex compared to $42 \%$ of the women. Thirty six percent of respondents stated that they had met their partners face to face whilst $41 \%$ said that they did not intend to marry their online partner in the future. Sixty three percent knew of a friend who had found love on the internet compared to $37 \%$ who said otherwise.

\section{Getting to know people of opposite sex}

Interaction and getting to know people of the opposite sex was one of the major themes that emerged from the interviews;

Samira a 30-year-old single woman stated that;

For a long time I wished to know people of opposite sex without worrying about my family, the internet has helped me in this regard. I have the freedom to choose who I want to speak to without having to look over my shoulders. I grew up in a conservative society, which forbids social contact between men and women.

Another female informant stated;

I am quite a chatty person and I like to talk to men. I am so glad I met my current boyfriend. He is just so different to those I met online. He is so honest about what he likes and dislikes (Saima: 36).

This is very much echoed by Hardey [43] who suggests people use the internet to meet and find relationships. There is a possibility of becoming over enthusiastic as one informant had this to say;

Chatting with women has become an addiction for me; 
every day, I spend hours talking to women from different countries, even whilst I am at work. Most evenings I chat until very late .... I do not feel guilty, some of these girls need to be loved, and they want to hear the word "I love you" (Sameer 37 Liberian).

Occasionally, friends and colleagues influenced the individual to go online, as one informant went on to say that;

I turned to online chatting after I divorced my wife, and found that the majority of my friends and colleagues had a partner online. So when a friend encouraged me to create an online account I agreed. He told me everything I needed to know about how to use MSN and Yahoo messengers. I did have a go and had some strange experiences, it got to the point where I was thinking it does not really worth the effort. My friends insisted and suggested that I should not give up hope. I spoke to some nice individuals but it was not possible to arrange to meet them because they lived abroad. Occasionally, I met people who were not nice at all (Abdulkarim 35 social worker).

Another male talking about his romantic exploits stated;

I have two online girlfriends, one is a Palestinian living in Gaza Stripe who works as a secretary, and the other one is a married American woman who is not happy with her marriage. We speak freely about sex. (Azam 28 businessperson).

\section{Presentation of self}

The following extract points to the fact that despite being able to know a lot about the people, which one meets online, one has to be aware that the information exchanged could be potentially incorrect, as some people would simply lie about themselves.

My friend actually set my profile up. I was 30 at the time and had my age as 8 years younger than I was. However, I was able to use the profile that she had created and started to chat. In a year, I had about two regular dates, but I soon found out that internet dating was overwhelmed with lies, silly little things like their education, job, their hobbies, etc. (Fatima 38).

\section{Improving social skills}

Improving social skills to interact with others was another major theme.

I was not very good at socialising in 'the real world', because I had very few friends and did not network to find new friends. I was very shy and never engaged with females as such. Using the internet has been good for me because I can get to know people, their opinions on marriage, politics, art etc. then you can decided whether you find them attractive or not (Eisa 32 computer engineer).

According to Rubin and Coplan [44] there are some individuals who are unable to communicate face-to face with a potential partner, the internet enables them to improve their social skills and utilize them in their face-to-face interaction.

\section{Finding online partners}

The majority of participants found their online partners by chance whilst others were given the email address of a potential partner by their friends;

I was surfing the net and I received a message from a man in Bahrain. He gave me his email and I added him to my yahoo contacts. It was not long before we became online partners (Salma 26 office worker).

His colleagues helped the following informant;

The world of online dating was alien to me, some of my younger colleagues introduced me to the game, and they acted as my guide, putting me in contact online with some women. I was just happy to chat to people and that was O.K., but when I began to chat to females, it became fun (Sameer 37 Liberian).

A computer engineer boasted about his success by stating that;

I had several online girlfriends and I found it hard to manage the time and keep up chatting with all of them, I passed on the email of one of them to a colleague to get her off my back, they became close friends (Eisa 32 computer engineer).

\section{Trust}

The respondents stated that once a connection was made, they started chatting first without using the webcam and then when they felt that they could trust the other person they started viewing each other.

There is a possibility of meeting someone who wants to "expose himself,". It happened to me once, after 30 minutes into chatting with a man he took his clothes off and asked me to do the same. There are some twisted people around who would take a snapshot of you share it with their friends or saved it for future use. I have met some seemingly trustful people but I do not easily allow them to see me unless I get to know enough about them (Fatima 38).

Echoing the same sentiments, Salma said;

When I chat to strangers, I do not share my webcam unless I want to take it further I because bad people could do many things with your images, like post it on-line. I always remind myself of not to give my details unless I have spoken to the person for a long period and know their identity, millions of people are looking for friendship and fun online. Some people who contact you genuinely just want to chat or be friends. However, the problem is, it is easy to lie online. Some people flirt with you, flatter you and ask to see your body with the intention to abuse you (Salma 26). 
Trust is central to formation of romantic relationships, especially online relationships. General trust and confidence shape the experience of online dating [45].

An internet café owner said that;

Computers and the internet are used for finding information, playing games, finding educational materials for student projects, talking to family members who are living and working abroad but mainly for chatting with the opposite sex. Those who want to chat to a boyfriend or a girlfriend ask for the webcam.

\section{Physical attraction}

After seeing and chatting online for a while most individuals felt physically attracted to the person and they started to move away from formalities to more intimate and romantic relationships. The informants indicated that the progression from friendship to romance required skill, motivation and action. It involved feelings of affection, romantic gestures and flirting, not surprisingly, the first move was invariably initiated by men. Once in love, the majority experienced some kind of emotional attachment, a need for going online, meeting each other and sharing affections.

\section{Normally women do not put their photo up for you to see, they do so after getting to know you. They have to feel comfortable with you. I received over 10 requests and added a few of them to my contacts. I finally met the right girl; it was a bit of a romance. We were living in different cities. We both travelled from our cities and met in another city for our first date a few months after we met online. I was not desperate but I thought why drag it? I feel I have found my soul mate. (Azam 28 businessperson).}

This confirms the claims by Levine [46] and Rambaree [47] that as the level of attachment over the internet increases intimacy increases too. However, one should note that most men are eager from the start to become intimate as Fatima, a 38 year old woman with a university degree who works for a cooperative suggested;

\begin{abstract}
I learned about online chatting from a colleague and soon found myself chatting to men from different countries.... Those men all were after one thing as you can imagine. Eventually I managed to find a real gentleman who I feel deeply in love with. We know each other for four years, he is a professional person and very honest.
\end{abstract}

Another female informant reflecting on her past experience said;

I have been on chat programs and been approached by some younger men who always saying age is not important or saying they prefer older women. The script is all the same, as if they all have been graduated from the same chatting school. About 20 or 30 minutes after the start of conversation they tell you they love you, they ask you to open your cam (Ruba: 42).

Both men and women contribute to the process of dating, nevertheless, men are more likely to ask for a date expecting women to be proactive in initiating a relationship [48].

\section{Expressing ones sexuality}

Participants felt that cyberspace was a suitable location to start personal interactions, as several participants, especially women, felt less inhibited in revealing their sexuality in this format. Cyber flirting started after chatting for some time and a relationship of trust had been formed, and the individuals felt more confident about themselves. Some decided to move to face-to-face relationships because they felt a strong need for physical contact and more intimacy. Other researchers have reported that some internet relationships will eventually progress to face-to-face relationships [46,47]. Moreover, given that Morocco has a well-developed tourist industry, relatively cheap hotels and restaurant it is an ideal place to meet for the first time.

Saima is a 36-year-old woman, and an expert computer user who has helped several young women with computer literacy, she suggested that;

I have had several experiences with men online in the past. One day I met the man of my dreams... I know him for almost 7 years. We soon felt in love. Until three years ago, we knew each other only by our first names and the rest did not matter. After 3 years of dating online, the need to physically meet became very strong. The problem was that he was living in Europe. He arranged to travel to Morocco and when we met for the first time it was very strange. He looked much younger and even more handsome in person compared to what I used to date online; he felt the same way about me too.

\section{Wanting to get marry}

One of the main reason for going online was to find a person to marry, ideally a person from the oil rich Gulf or Europe, given the high levels of unemployment whilst marriage is becoming very expensive, it is no wonder why so many young women are trying to find a marriage partner abroad as Johnson-Hanks [49] elaborates;

Women seeking foreign husbands on the Internet are doing something counterintuitive: using a new, transnational technology to achieve old, local aims when the old, local methods for achieving those aims no longer suffice [49] p.655.

One participant stated that her cousin found her husband using the internet:

He is an Iraqi who lives in Germany. After couple of years of chatting online, they felt deeply in love. He came to visit my cousin in Morocco and he decided to 
approach her family. First, her parents were not sure because of cultural differences but eventually they gave in and blessed the engagement (Zara 24 student).

Sometimes patience and perseverance results in success as it is revealed by the following extract;

My sister in law's cousin left Morocco when he was very young; he was a member of a cyber cafe in Marrakech, chatting almost every day for two years. He was communicating with women from other countries, wanted to know about other cultures and civilisations, trying to meet women and share thoughts and ideas. One day he met someone in a chat room and after couple of days they felt that they could talk, they exchanged telephone numbers and within a month she flew to Morocco, they got married and soon after he was on a plane going to USA (Azam 28 businessperson).

Marrying a foreigner from a more developed country would enable people to leave their country and move abroad for a better future;

You will be amazed at the number of internet cafes that are in the city relative to its size. I have about 12 computers, usually; one or two people are using each station. The majority are young especially after dark. The older people often find it hard to use computers outside the college and high school hours. Most users come to chat and they are very serious. We have our regulars; some spend about 4 to 5 hours a day and chat to foreigners, especially French and French Canadians. They are looking to find a marriage partner to get out of Morocco. I have heard of people who have been lucky and found someone and now living abroad (Internet Café owner).

The internet increase the chances of finding a suitable partner as the following quote shows;

I thought that my chances of meeting the kind of person that I would like to marry were limited offline, because the way our culture is. I wanted a man who was not the same as most Moroccan men. (Samira 30)

Acknowledging that the internet could potentially help people to find a marriage partner, this informant points out the need for cultural adjustment;

If you are serious and really want to find a marriage partner, it really helps to use the net because it enables you to get to know the person from the inside out. In our culture, you do not usually have enough time to get to know your future spouse. Normally, the marriage takes place soon after the engagement. I think that online dating would help our society, but it will require a cultural change. (Abdulkarim 35 social worker)

One informant blamed the economic and political situation as one possible cause for people wanting to marry and emigrate;

It has a lot to do with the economic and political situation in Morocco. The youth are driven by despair and it seems there is no way out. There is very little hope for us, getting married is too expensive, good paid jobs are scarce even if you have a good education (Sameer 37 Liberian).

\section{Empowerment}

All participants felt that the internet provides paths to empowerment. This empowerment was expressed in terms of ever increasing political, social and cultural awareness, development of social networks, and access to a wealth of information and education. According to Wheeler [50] the internet empowers its users but this empowerment is contextualised since many in developing countries do not have access to the internet.

Ruba a 42 year divorced woman who was originally introduced to the net by her ex-husband, and has internet access at home and uses the internet to communicate with her brother and sister in Spain went on to say that;

The internet has opened the world to me, instead of feeling isolated like many divorced women in my country, I use the internet to find information, listen to music, watch videos, and talk to my family. It is a lot cheaper to use the internet than making international calls and you can see your loved ones. ....at the beginning I found it very hard to talk to strange men, I have found a Lebanese soul mate who works in the Gulf.

\section{Anonymity}

According to Christopherson [51], anonymity allows people to experiment with new forms of behaviour without being afraid of the social consequences.

A young female informant had this to say;

In early days, I probably was not quite so straight with him because I was new to this and was testing the water. There are disadvantages in online relationship; people might be different to who they say they are, but you feel safe because you are in control, they do not really know who you are unless you want them to, and you can cut off communication straight away. (Salma 26 office worker)

Postmes \& Spears [52] state that anonymity frees individuals from their long-established roles and enables them to act in a manner, which is not by and large expected of them. As Gauntlett [53] states;

Since participants .... are not obliged to reveal their names or physical location, there is considerable scope for people to reveal secrets, discuss problems, or even act whole identities, which they would never do in the real world. (p.14) 


\section{Overcoming Social and cultural barriers}

Overcoming socio-cultural barriers, which for long kept the two genders apart, was another key theme;

After centuries of not being able to talk to the opposite sex, not being able to discuss and express your feelings, your emotions and your sexual energy; the internet and the webcam has enabled the youth .......[to] express their feelings without fear of being caught (Abdulkarim 35 social worker).

The following quote highlights the fact that social relationships between opposite sexes are culturally problematic;

You could find a girlfriend offline, in doing so, you have many headaches, and you have to be prepared for scandal. The internet makes the whole process smarter and much more efficient (Eisa 32 computer engineer).

A female university student elaborated;

We have grown up within a culture that allows natural desires and sexual relationships within marriage and forbids these relationships outside marriage. The internet has provided an escape route for the youth, they can find friends, girlfriends, boyfriends online without being judged (Zara 24 Student).

All respondents agreed that using the internet for dating and interaction with the opposite sex was not socially acceptable but they believe that since the internet provides them with anonymity and in most cases, they are interacting with people from other countries, the possibilities of being found was minimised.

It makes me laugh when I think about my first encounter online with the opposite sex. I was so nervous because I felt that I should not really be doing this. I have met a few people before my current boyfriend online, some were nice people, interesting, Kind of men that I could talk to about travel and music and books and my hobbies in both Arabic and French. However, I think the advantage of online dating, is that some of the more traditional avenues are no longer meet the demands of modern times. For example, when you meet somebody in a gathering you only cover basic questions and information. Whereas the amount of information that you can find out about someone online is a lot more than you might ever know about someone that you know casually. (Fatima 38).

Talking about the kind of challenges that people have to face this informant stated;

I know of a young woman who has been dating her boyfriend for about 18 month and she discovered she was pregnant. She had to have an abortion against her wish but did not have any choice. She had a terrifying time because abortion is illegal. There are some doctors who help desperate women. Her family know nothing of her ordeal..... I have been with my current boyfriend for eight months but apart from my closest friend who occasionally covers up for me, and provides an alibi, nobody else knows about this. All those young women who start dating men are taking huge risks but they are human beings and have their own personal needs. They cannot change our society; they do not have the courage to challenge people beliefs directly, especially their fathers and their brothers (Saima 36).

Azam 28 has several serious relationships. He has had sex many times and does not feel guilty.

My parents and family members do not know about this, I cannot talk about these matters. I think everybody knows that men are able to have access to sex in this country if they wish to but everybody is quiet about it. Spending the night together is difficult because most people live at home with their families. You can go to a hotel, check into different rooms, and sneak between them.

Zara 24 highlights the hypocrisy surrounding attitudes towards premarital sex in Moroccan society by saying that;

I was with my boyfriend for one year. We did not have full sex because our traditions stopped me. I felt guilty about what we did but I am still a virgin. Sadly, our society is particularly hypocritical and in self-denial. A person has to feel guilty about her natural desire to have intimate relationship because it is considered taboo by the society. Premarital sex is forbidden in Islam and in our culture but it happens, people think about it but they do not admit it. Men are lucky because they do not have to prove that they are virgin, they engage in premarital sexual relationships whilst at the same time expect the women to be virgin. Most men have sex with a number of women but the very men will not consider marrying a woman if she had some non-penetrative sexual experience.

All informants agreed that premarital sex is forbidden in Islam, and that interaction with the opposite sex was culturally and socially problematic. They also stated that despite religious and cultural barriers pre-marital sex existed but not in an open and honest way. This highlights the fact that cultural homogenization has not really taking place as the result of globalization, and the medium of the internet, for the very simple reason, If the Western cultural norms had been incorporated to the Moroccan culture then people of both sexes would freely engage in intimate relationships without worrying about their families, future marriage prospects, their reputation as a decent person, honour of their family etc. 


\section{Consequences of Being Caught}

The consequences of being caught for women were extremely serious; highlighting that Morocco has not yet incorporated Western cultural norms. Global cultural homogenisation is far from being materialised at least so far as interaction between opposite sexes are concerned. Bakass \& Ferrand [37] p.37 argue "The social and religious order in Morocco is still based on such values as the honour and good name of the family wherein premarital female sexuality is proscribed and an intact hymen is irrefutable evidence of a successful family upbringing". This is evident from the following extracts;

Both her family and the society will treat a girl harshly who brings shame and disgrace to her family....if neighbours and others hear about it they would spread the news, they will gossip, no body then would want to marry you, and your life is ruined forever. (Samira 30)

Another female went on to say that:

Even thinking about what might happen scares me. I am sure my father will go mad....I know he will throw me out. (Salma 26 office worker)

All informants were involved in networking across different cultures. Networking enabled them to form relationships with the opposite sex within a safe and secure environment, enabling individuals to test various life styles, acquire knowledge and enhance their understanding of other cultures whilst improving their language skills. The informants were mostly locked into their own local networks and often saw them as repetitious, non-exciting and routine. Despite having weak ties, it was the leap into the global networks, which stimulated them.

\section{Conclusions}

This paper aimed to explore Moroccans adults' construction of internet-mediated romance whilst overcoming social cultural barriers, and whether this experience was related to global cultural homogenization. Using a mixed method approach, we found that the majority of respondents used the internet for communication, finding information, watching movies, listening to music, and chatting/dating, and knew of someone who had found love online. The internet helped them to find a partner of opposite sex, provided anonymity, helped them to overcome cultural barriers to romance, and empowered them, especially women. However, despite using the internet and enjoy interacting with the opposite sex, the powerful social and cultural norms were ever present to remind them that their way of life is very much different to Westerners. The internet offers a buffer zone in which members of the opposite sex can interact without crossing spatial boundaries. It enables individuals to move out of the local and enter the global simultaneously and create and experience new life styles. Even while they retain their own cultural values, they experiment with Western culture. For women, protection of her family reputation and honour remains very important but the internet allows her to experience romance while conforming to traditional values. For men, the internet helps in finding sexual relationships. Far from being a tool for cultural homogenization and imperialism, the internet allows people to create and test life styles that are very much related to individuals' identities. These identities are constructed and formulated when people who live in their localities, still tied to custom and locale, nevertheless become exposed to cultural flows which they incorporate into their own lives. Individuals construct life styles often knowingly from global images, and test them out against the backdrop of their own cultural forms [54,55,4]. When People chat online and form friendships and romances with others, globally, they are forming communities of sentiment [52,4] with those who share the same corresponding life styles.

Globalization is changing the world, our societies and our daily experiences. Yet, whilst our societies are being transformed, the established institutions often fail to keep up with these transformations. Young people in developing countries have the same aspirations, needs, and desires as their counterparts worldwide. Thus, when their desire to interact with people of the opposite sex is repressed by culture and tradition we are likely to find dishonesty, subterfuge, and hypocrisy. Wheeler [56] p.21 argues that technology does not determine social outcomes but it provides 'a way to conduct meaningful social practice'.

Much of current debates on globalisation, and the emergence of a global culture draw on a narrow and simplistic notion of culture, assuming people and their culture could be easily changed. Culture refers to commonly shared ideas, language, beliefs systems, customs, myths, literature, music, knowledge, etc. it represents the way of life of a society, which evolves over centuries and become diffused in the general psyche of a nation. The Moroccan culture has been in the making for centuries. In recent times, it was challenged by forty-four years of French rule, this encounter failed miserably to change Moroccans attitudes towards premarital sex and interaction between sexes. Accordingly, developing romantic relationships on line on the part of some citizens is unlikely to result in the complete incorporation of Western sexual attitudes and cultural practices into Moroccan society.

\section{REFERENCES}

[1] Cohen. R, Kennedy. P. 2013. Global Sociology. Third Edition. Palgrave Macmillan.

[2] Anderson. J. W. 2003. New Media, New Publics: Reconfiguring the Public Sphere of Islam. Social Research70 (3): 887-906. 
[3] Bernal. V. 2005. Eritrea on-line: Diaspora, Cyberspace, and the Public Sphere. American Ethnologist 32 (4): 660-675.

[4] Fair. J. E, Tully. M, Asante. R.K.B. 2009. Crafting Life Styles in Urban Africa: Young Ghanaians in the World of Online Friendship. Africa Today 55 (4) 29-49.

[5] Miller, D., Slater, D. (2002). Relationships. In Askew, K., Wilk, R. (Eds.). The Anthropology of Media. Oxford: Blackwell.

[6] Rheingold. H: 2000: The Virtual Community Homesteading on the Electronic Frontiers. Cambridge. Mass, MIT Press.

[7] McMahon. P. 2001. Technology and Globalization: An Overview. Prometheus 19 (3) 211-222.

[8] McMahon. P. 2002. Global Control: Information Technology and Globalization since 1845, Edward Elgar Publishing Limited, Cheltenham UK and Northampton MA, USA.

[9] Featherstone, M. 1990. Global Culture: an Introduction, in Featherstone, M. (ed.) Global Culture: Nationalism, Globalization and Modernity. London Sage.

[10] Scholte, J. A. 2005. Globalization: A Critical Introduction. Basingstoke. Palgrave Macmillan.

[11] Held. D, McGrew. A. 2003. The Global Transformations Reader: An Introduction to Globalization Debate. Polity Press Blackwell.

[12] Hannerz, U. 1992. Cultural Complexity: Studies in the Social Organization of Meaning. New York. Colombia University Press.

[13] Canclini. N. G. 1995. Hybrid Cultures: Strategies for Entering and Leaving Modernity. Minneapolis. MN: University of MinneapolisPress.

[14] Howes. D. (ed.). 1996. Cross-Cultural Consumption: Global Market, Local Realities. London. Routledge.

[15] Tomlinson. J. 1999. Globalization and Culture. Cambridge. Polity.

[16] Ritzer. G. 2004. The McDonaldization of Society. Thousand Oaks. CA: Pine Forge Press.

[17] Chaney. D. 1996. Lifestyles. London. Routledge.

[18] Chaney.D.2001.From Ways of Life to Lifestyles: Rethinking Culture as ideology and Sensibility. In Culture in the Communication Age, James Lull (ed.). London: Routledge.

[19] Appaduri. A. 1996. Modernity at large: Cultural Dimensions of Globalization. Minneapolis: University of Minnesota Press.

[20] Padilla. M, Hirsh. J. S, Munoz-Laboy. M et al. (eds.) 2007. Love and Globalization: Transformations of Intimacy in the Contemporary World. Nashville. TN: Vandebilt University Press.

[21] Valentine. G. 2006. Globalizing Intimacy: the Role of Information and Communication Technologies in Maintaining and Creating Relationships. Women Studies Quarterly. 34(1/2). 365-93.

[22] Illouz. E. 2007. Global Intimacies: the Making of Emotional Capitalism. Cambridge. Polity.
[23] Altman, D. 2001. Global Sex. Chicago and London: University of Chicago Press.

[24] Jackson. P. A. 2009. Global Queering and Global Queer Theory: Thai [Trans] genders and [Homo] sexualities in World History. Autrepart 1 (49) 15-30.

[25] Blackwood. E. 2005: Transnational Sexualities In One Place: Indonesian Readings. Gender and Society 19 (2): 221-242.

[26] Obermeyer. C. M. 2000. Sexuality in Morocco: Changing Context and Contested Domain. Culture, Health and Sexuality 2 (3) 239-254.

[27] World Factbook:2014. Washington, DC: Central Intelligence Agency. 2014.

https://www.cia.gov/library/publications/the-world-factbook/ geos/mo.html. Accessed 30/05/2014.

[28] Norris. P, Inglehart. R. 2004. Sacred and Secular. New York: Cambridge University Press.

[29] Bowen. D. L. Green. A, and James. C. 2008. Globalization, Mobile Phones and Forbidden Romance in Morocco. : The Journal of North African Studies: 13 (2) 227-241.

[30] Newcomb. R. 2006. Gendering the City, Gendering the Nation: Contesting Urban Spaces in Fes, Morocco. City and Society 18 (2) 288-311.

[31] Venema. B. Bakker. J. 2004. A Permissive Zone for Prostitution in the Middle Atlas of Morocco. Ethnology 43(1) 51-64.

[32] Kaya. L. P. 2009. Dating in a Sexually Segregated Society: Embodied Practices of Online Romance in Irbid, Jordan. Anthropological Quarterly 82 (1) 251-278.

[33] Macleod. A. E.: 1991: Accommodating Protest: Working Women and the New Veiling in Cairo. New York. Columbia University Press.

[34] Mernissi. F. 1982. Virginity and Patriarchy. Women's Studies Int. Forum 5 (2) 183-191.

[35] Atighetchi. D. 2007. Islamic Bioethics: Problems and Perspectives. Springer. The Netherlands.

[36] Sougrati.A.2011. Young Moroccans: Profile, Expectations and Perceptions.

http://www.statistics.gov.hk/wsc/STS069-P2-S.pdf. Accessed 20/10/2015.

[37] Bakass. F, Ferrand. M. 2013. Sexual Debut in Rabat: New "Arrangements" between the Sexes. Population Vol. 68, 2013/1, p. 37-59.

[38] Castells. M. 1997. The Power of Identity. Oxford. Blackwell.

[39] Internet World Stat. 2011. www.internetworldstat.com. Accessed 28/6/2012.

[40] Charmaz. K. 2006. Constructing grounded theory: A practical guide through qualitative analysis: London. Sage.

[41] Boeije. H. 2010. Analysis in Qualitative Research: London. Sage.

[42] Glaser. B. and Strauss. A. L. (1967). The Discovery of Grounded Theory: Strategies for Qualitative Research. Chicago. Aldine. 
[43] Hardy. M. 2004. Mediated Relationships: Authenticity and the Possibility of Romance. Information, Communication, and Society 7 (2) 207-222.

[44] Rubin. K, Coplan. R. 2010. The development of Shyness and Social Withdrawal. Guilford Press. London.

[45] Fiore. A. T, Cheshire, C. 2010. The Role of Trust in online Relationship Formation. IGI Global.

[46] Levine. D. 2000. Virtual Attraction: What Rocks Your Boat. Cyber Psychology and Behaviour 3 (4) 565-573.

[47] Rambaree. K. 2008. Internet Mediated Dating/Romance of Mauritian Early Adolescents: A Grounded Theory Analysis. International Journal of Emerging Technologies and Society 6 (1) $34-59$

[48] Strong. B, Cohen. F. 2014. The Marriage and Family Experience: Intimate Relations in a Changing World. 2014. Wadsworth. USA.

[49] Johnson-Hanks. J. 2007. Women on the Market: Marriage, Consumption, and the Internet in Urban Cameroon. American Ethnologist 34 (4) 642-658.

[50] Wheeler. D. L. 2007. Empowerment Zones? Women, Internet Cafés, and Life Transformations in Egypt.
Information Technologies and International Development 4 (2) $89-104$

[51] Christopherson. K. M. 2007. The Positive and Negative Implications of anonymity in Internet Social Interactions: On the Internet, Nobody Knows You're a Dog. Computers in Human Behaviour 23, 3038-3056.

[52] Postmes. T. \& Spears. R. 2002. Behaviour Online: Does Anonymous Computer Communication Reduce Gender Inequality? Personality and Social Psychology Bulletin 28 (8) 1073-1083.

[53] Gauntlett. D. 2000 (ed.). Web Studies: Rewriting media Studies for the Digital Age. London. Arnold.

[54] Kennedy. P. \& Danks. K. 2001. Globalization and National Identity: Crisis or Opportunity? Palgrave Macmillan. Basingstoke.

[55] Beck, U. and Beck-Gernsheim. E. (2002). Individualization: Institutionalized Individualism and its Social and Political Consequences. London. Sage.

[56] Wheeler. D. L. 2006. The Internet in The Middle East: Global Expectations And Local Imaginations In Kuwait. New York. State University of New York Press. 